\title{
Meio século de interpretações sobre o rural brasileiro (1968-2018)
}

\author{
Interpretations about Brazilian agrarian development \\ over a period of half century (1968-2018)
}

\author{
Zander Navarro ${ }^{1}$
}

\begin{abstract}
Resumo: o presente artigo discute as principais narrativas intelectuais e acadêmicas que analisaram "o rural brasileiro" pelos ângulos disciplinares das Ciências Sociais, nos últimos 50 anos. $\mathrm{O}$ artigo identifica a existência de temas originais, alguns duradouros, em função da história social do País, reconhecendo a partir da década de 1970 um período aproximado de 20-25 anos que representa a fase mais profícua de tais estudos. Conclui que no presente século tem ocorrido um arrefecimento de interesse nos estudos rurais, especialmente na Sociologia e na Antropologia, e uma crescente hegemonia de enfoques da Economia Rural de tradição neoclássica.
\end{abstract}

Palavras-chaves: Brasil rural, modos de interpretação dos processos sociais e econômicos, tradições intelectuais e acadêmicas sobre o rural brasileiro.

\begin{abstract}
: the article discusses the main intellectual and academic narratives that studied "the rural" in Brazil through the focus of the disciplines of Social Sciences over the last 50 years. It suggests that there are several original themes, some of them persistent because of the social history of the country. Starting in the 1970s, there is a period of approximately 20-25 years that represents the richest phase of these studies. The article concludes that, in the current century, a diminishing interest in rural studies has been observed, especially in Sociology and Anthropology, and a growing hegemony of interpretations linked to the neoclassical tradition of Rural Economics.
\end{abstract}

Key-words: Rural Brazil, social and economic processes and their modes of interpretation, intellectual and academic traditions about rural domains in Brazil.

Classificação JEL: N01, N56, 054, Z10.

Data de submissão: 21 de dezembro de 2018. Data de aceite: 13 de agosto de 2019.

1. Empresa Brasileira de Pesquisa Agropecuária (EMBRAPA), Brasília (DF), Brasil.

E-mail: z.navarro@uol.com.br 


\section{Introdução}

É necessário reconhecer inicialmente que ainda não existem esforços de análise consolidados no Brasil que tenham esmiuçado a história intelectual das ideias centradas no "rural". Assim, este artigo ambiciona iluminar algumas trilhas em uma floresta que se mantém quasi-original ${ }^{1}$. É notório que as Ciências Sociais (incluindo a Economia) constituem um campo multidisciplinar fraturado por intensos desacordos. O presente artigo propõe uma análise que se estende por cinco décadas, assim buscando oferecer inteligibilidade explicativa sobre as profundas transformações ocorridas no "mundo rural" e os seus correspondentes modos de interpretação. Considera, igualmente, a vasta dimensão do País, refletida em numerosas diferenças regionais, como também os impactos produzidos pela tradição da literatura francesa vis-à-vis as demais tradições competidoras europeias e a escassa presença de contribuições norte-americanas exceto na Economia. A influência francesa na Sociologia e Antropologia tem sido persistente, embora menos presente na análise econômica e na Ciência Política.

Referidas as limitações acima, o artigo não é nem a síntese de uma teoria ou arcabouço destinado a sustentar a explicação sobre os processos sociais rurais (o que

1 Como exemplo do desinteresse que mantemos sobre esta história intelectual, é surpreendente que a melhor análise sobre a formação e o estabelecimento da Sociologia Rural no Brasil tenha sido publicada em 1971, e nenhum esforço de similar ambição tenha sido empreendido desde então. Sugere-se consultar o pioneiro relatório de José Arthur Rios (Rios, 1971). seria uma nova interpretação) e nem uma abrangente ou completa descrição de noções, categorias ou modelos que tenham influenciado os estudos rurais no País nas últimas cinco décadas. Estrutura-se, antes, sobre dois objetivos principais. Primeiramente, submeter um panorama das principais vicissitudes experimentadas pelas trajetórias intelectuais que seriam merecedoras de menção, mas não de hierarquização, representando um esforço de seguir a orientação do lendário medievalista Marc Bloch, que alertou que "a tarefa do historiador é entender, não julgar". Em segundo lugar, argumentar que o período temporal analisado, meio século (1968-2018)2, tem sido claramente caracterizado por um processo de crescimento contínuo da economia agropecuária (especialmente intensificado nos últimos 20 anos) e, de fato, esse contexto produtivo é o campo de batalha real das ideias que disputam explicar a essência do desenvolvimento agrário brasileiro.

Sem as restrições do espaço disponível, o tema poderia ser ricamente ilustrado por eventos, autores, controvérsias, referências factuais ou até mesmo momentosas disputas ideológicas, adensando a explicação das trajetórias intelectuais. Como consequência, três enfáticas advertências são necessárias nesta introdução.

Primeiramente, em face do desafio territorial gigantesco, existem sub-regiões que amadureceram ricas narrativas específicas que já acumularam bibliografia própria e obrigatória ao longo do tempo. Bastaria refletir sobre os

2 A explicação para o corte de cinco décadas, iniciado em 1968, foge às ambições desse artigo. Ver Navarro \& Pedroso (2019). 
inúmeros estudos relativos à região amazônica ou, então, sobre o Nordeste rural. A primeira tem sido objeto de estudos, pesquisas e obras diversas que se debruçaram sobre a complexidade de uma enorme região que entrelaça em suas análises diferentes interesses (inclusive internacionais), comunidades indígenas ou correntes migratórias. Abarca, especialmente, os mistérios de sua natureza, ainda desconhecida em diversos aspectos.

O Nordeste, por sua vez, é o determinante originário principal de numerosos aspectos da história social, cultural e econômica do País, desde os primórdios da colonização. Por isso, os intelectuais da região produziram uma volumosa coleção de obras dedicadas a explicar o desenvolvimento social do Nordeste. Como não existe a chance de discutir aqui as particularidades daquela região no tocante aos processos sociais rurais, esta é uma tarefa intelectual ainda pendente.

Em segundo lugar, exceto por uma brevíssima referência, não serão registrados e nem avaliados outros detalhes sobre a institucionalização promovida, a partir da década de 1970, dos campos disciplinares das Ciências Sociais que enfocam "o rural" - por exemplo, a gênese e os resultados de programas de pós-graduação, revistas especializadas, encontros acadêmicos regulares, sociedades científicas e outros fatos similares. E como terceira advertência inicial, as mesmas limitações de espaço impedem nomear os responsáveis e os esforços abrigados no subtema da "formação acadêmica". Diversas narrativas intelectuais receberam robustos reforços em função da ação individual realizada por notáveis pesquisadores, orientadores de pós-graduação ou professores. Contudo, muitos deles foram (e são) brilhantes nessas atividades, mas comedidos produtores de publicações científicas. O resultado é que são autores de poucas evidências tangíveis de pesquisa. E sem provas públicas, é quase impossível associar concretamente esses colegas ao peso específico de algumas tradições intelectuais sobre "o rural" no Brasil, pois seriam avaliações excessivamente subjetivas.

Por conseguinte, os nomes e publicações citadas nesse artigo são meros exemplos de "momentos especiais" que emergiram durante o período citado, quando debates específicos ou argumentos influentes ocorreram durante certo tempo. Em face dessas particularidades e nuances, o que está sendo proposto, muito provavelmente, encontrará maior recepção crítica do que a pronta aceitação. É assim um esforço preliminar de interpretação que talvez possa estimular futuras iniciativas similares que contribuam para enriquecer o debate sobre as Ciências Sociais e "o rural" no Brasil.

O artigo é constituído de três seções e a primeira sugere concisamente que os contextos rurais desenvolveram ao longo do tempo um lugar profundamente enraizado na consciência social dos brasileiros como "ideias força", especialmente por serem manifestações diretas de aspectos infames de nossa história, notadamente a escravidão. Esses temas, contudo, foram objeto, como regra geral, de leituras apenas especulativas, sem rigor teórico ou mesmo evidências empíricas consistentes - pelo menos até meados da década de 1970. Naqueles anos, dois assuntos fundadores motivaram os primeiros ensaístas sobre o rural brasileiro: o primeiro deles, o "peso (social) das grandes propriedades" - os latifúndios, historicamente nascidos da assimétrica distribuição da terra. O segundo pilar, como consequência, foi a "estreiteza dos mercados internos". Esses dois ângulos de interesse contribuíram para desenvolver duas linhagens teóricas hostis entre si em relação ao papel da agricultura e das regiões rurais e suas populações na estruturação do capitalismo e da sociedade. Ou seja, seguindo o jargão dos economistas, o papel da agricultura no padrão de acumulação de capital e os mecanismos através dos quais o excedente iria contribuir para assegurar a industrialização e a expansão econômica.

A primeira perspectiva poderia ser intitulada de "visão agrária" (ou "agrarista"), pois discutia predominantemente os temas sociais e culturais e enfatizou "o peso da concentração da terra", desta forma acentuando o poder econômico e político dos grandes proprietários, também discutindo as dramáticas condições vigentes no mundo do trabalho e os conflitos corriqueiros - em síntese, a "questão agrária" lato sensu. Já a segunda linhagem dos estudos, naqueles anos, centrava-se nos aspectos econômicos e financeiros e, portanto, privilegiava os temas da produção e da modernização tecnológica. Poderia ser intitulada como uma "visão agrícola" das mudanças então em curso no campo. Examinadas a partir de uma transição ocorrida ao longo de cinco décadas, estas perspectivas explicativas (ou estes modos de interpretação) vêm competindo, desde então, pela hegemonia da comunidade de cientistas sociais, com a "visão agrária" prevalecendo até recentemente. A recente e acelerada expansão do setor agropecuário, contudo, inverteu tal ordem e, atualmente, a "visão 
agrícola" gradualmente vem suplantando a narrativa agrária. Ao mesmo tempo, a relação intelectual entre as disciplinas das Ciências Sociais tem-se alterado, porque um número crescente de sociólogos e antropólogos vem abandonando esse campo de estudos, abrindo pari passu os espaços para a dominância dos economistas abrigados nos modelos mainstream.

A segunda seção do artigo discute os chamados "anos dourados" da produção científica que analisou o mundo rural, período que se estendeu, grosso modo, entre a segunda metade dos anos 1970 à década de 1980, mas foi mudando a sua essência e começando a agonizar perto do final dos anos 1990. Esse período intermediário durou aproximadamente duas décadas e foi marcado pelo crescimento do número de pesquisadores e pela expansão da pesquisa e da produção científica. Foi também um período caracterizado pela institucionalização definitiva das Ciências Sociais ditas "rurais", tendo como pano de fundo a lenta transição entre um rural agrário ancorado no passado e a emergência de um país crescentemente dominado pela vida urbana. Mas, a despeito do crescimento persistente de uma economia agropecuária moderna, as interpretações agrárias, durante esses anos, ainda prevaleceram, animadas pelos impactos políticos da democratização que se seguiu ao fim do regime militar em 1985.

A terceira seção analisa os últimos 20 anos e sugere a existência de uma gradual erosão de interesse sobre os estudos rurais. Nesses anos têm sido observadas perplexidades teóricas mais desafiadoras, fragmentação analítica e, notavelmente, excessos claramente ideológicos - especialmente no campo sociológico. A Economia rural, contudo, tem ampliado sua relativa hegemonia em correspondência ao espetacular crescimento da economia agropecuária brasileira nesse século. Em consequência, como seria impensável desmentir empiricamente a afirmação de um modo de acumulação globalizado que é típico (cada vez mais) do capitalismo nas áreas rurais brasileiras, a história dos últimos cinquenta anos demonstra uma inversão no campo das ideias e suas teorias. As trajetórias da pesquisa e da explicação científica têm observado a perda de influência de vertentes influenciadas pela "visão agrária" e a crescente influência, sobretudo, das escolas explicativas da Economia Rural que afirmam a ordem social.

\section{Raízes contextuais}

Diversos fatos, tendências e processos anteriores a 1970 contribuem para explicar os 50 anos seguintes, que é o intervalo de tempo que enquadra a rota analítica desse artigo. A capilaridade (no tempo e no território) de diversos processos estruturais profundamente enraizados, os quais antecederam o meio século seguinte, ainda conforma diversas tendências atuais. Não se trata apenas da faceta óbvia, que é a estrutura de propriedade da terra e seu legado, mas também os comportamentos sociais. Esses, em inúmeras manifestações atuais, são ainda um espelho do passado remoto em diversas regiões rurais brasileiras.

Os temas rurais eram fortemente presentes na agenda pública nos anos 1950 e 1960. Naquela época, a maioria dos brasileiros morava em regiões rurais e vivia sob os imperativos de uma dominante economia agrícola, centrada, em especial, na produção de café - cujo epicentro era São Paulo, com uma segunda órbita em torno das regiões produtoras de cana-de-açúcar no Nordeste. Contudo, algumas transformações profundas eram então iminentes. Em pouco mais de uma geração - entre 1940 e 1980 - essa maioria deixou o campo e mudou-se para as cidades. Enquanto $70 \%$ da população vivia no campo em 1940, a mesma proporção já habitava as cidades, em 1980. Atualmente esta última proporção atinge $86 \%$ do total da população.

Porém, durante as duas décadas citadas acima (o pós-guerra), a literatura sobre os temas rurais era escassa e também pobremente analisada, com raras exceções. Uma dessas foi Os donos do poder, de Raymundo Faoro (1958), um estudo que pioneiramente introduziu categorias weberianas para analisar a gênese e a evolução da formação social baseada na apropriação privada da terra desde os tempos coloniais. Outra obra-prima foi Os parceiros do Rio Bonito, de Antônio Cândido (1964), um livro que talvez pudesse ser emoldurado como a referência original dos estudos rurais "pré-científicos" no Brasil. Trata-se de uma rigorosa investigação empírica, de natureza antropológica, que estudou "o modo caipira de vida", então comum nas regiões rurais, assentado em famílias de arrendatários pobres imersos em uma rede de laços de subordinação aos proprietários. Era uma sociedade rural que estava desaparecendo em função das migrações seduzidas pela industrialização paulista, posteriormente a constituição de uma sociedade de 
massa e, recentemente, mudanças também associadas à chegada dos direitos no campo e aos impactos da globalização. Era um modo de vida ancorado em uma forma de produção pré-capitalista lentamente deslocada pela modernização econômica.

A vasta bibliografia de um dos mais importantes economistas brasileiros, Celso Furtado, dedicou frequente atenção aos temas agrícolas e rurais relacionados à economia brasileira. Meramente como ilustração, em Perspectivas da economia brasileira (1958), Furtado escreveu: “(...) a inexistência de uma agricultura moderna baseada no capitalismo e fundada no mercado doméstico é largamente responsável pelo desequilíbrio observado no país (...) [Como resultado] a incapacidade da agricultura em responder à crescente demanda por alimentos nas áreas urbanas constitui-se em um verdadeiro obstáculo ao desenvolvimento industrial" (apud Castro, 1969, p. 88) . $^{3}$ Entretanto, não obstante o brilhantismo analítico de Furtado, naqueles anos a maioria dos trabalhos publicados era visivelmente pobre em termos conceituais e se utilizava de evidências empíricas esparsas e insuficientes.

Ainda que a proposição acima seja simplificadora, seria impossível nesse curto artigo sintetizar os principais e diversos "entendimentos sobre a vida social e a produção no campo" anteriores a 1970 que tipificaram esses dois modos de interpretação antes referidos. Em ambas as vias de explicação, a narrativa raramente separava a interpretação das escolhas políticas e ideológicas dos autores ou do mero ensaio especulativo. Ainda não haviam sido sedimentadas as divisões disciplinares das Ciências Sociais e os recursos metodológicos eram diminutos, resultando assim em esforços de "ensaístas discutindo o Brasil", com argumentos especialmente retóricos. A maioria desses autores invariavelmente examinou a história e sustentou que o deletério desenvolvimento social do País tinha uma única causa - a concentração da terra, desde os primórdios da colonização. Estão incluídos nesse grupo até mesmo autores clássicos que escreveram no século 19, como Joaquim Nabuco, que relacionou a escravidão com a necessidade de reformar a estrutura de propriedade da terra em O abolicionismo, publicado originalmente em 1883.

Uma das análises específicas de Celso Furtado (1972) sobre o tema está sintetizada no artigo intitulado "A estrutura agrária no subdesenvolvimento brasileiro", que compõe o livro, do mesmo autor, Análise do modelo brasileiro (Rio de Janeiro: Civilização Brasileira, 1972, p. 91-120).
Consequentemente, os estudos que enfatizaram "a maldição da terra" prevaleceram durante os anos 1950 e até muitos anos após o golpe militar de 1964. Eram assuntos colados à agenda pública, sobretudo nos anos anteriores à ruptura institucional. Foi quando a assim chamada "questão agrária" (e suas demandas sociais decorrentes), além do clamor pela reforma agrária, vieram à tona na cena política. Processos políticos do período também contribuíram - da emergência das Ligas Camponesas, no Nordeste à ação do Partido Comunista Brasileiro (PCB), tentando formar sindicatos de trabalhadores em zonas de assalariamento rural. $\mathrm{O}$ artigo referencial sobre essas lutas sociais continua sendo o clássico "Os camponeses e a política no Brasil" (Martins, 1981). Contudo, esse foi debate conduzido, sobretudo, por intelectuais que, em sua maioria, orientavam-se por um arcabouço marxista de algum primarismo conceitual (Marighela et al., 1980), embora muitos pesquisadores não militantes também propusessem explicações sob o mesmo veio teórico (consulte-se, por exemplo, a coleção de ensaios organizada por Stédile, 1994).

O debate "agrarista" foi amplamente difundido na época, incluindo a demanda por reforma agrária e, por isso, o primeiro presidente após o golpe militar assinou o Estatuto da Terra, em novembro de 1964. O documento estabeleceu todos os procedimentos para implantar um programa de redistribuição de terras - se o governo assim desejasse (o que não ocorreu). Outro exemplo da turbulência política do período foi a greve dos trabalhadores rurais do Nordeste, em 1963, que continua sendo o maior de todos os movimentos grevistas de trabalhadores na história rural do País. Sobre esse tema e outros correlatos, os estudos de Raimundo Santos sobre a produção científica de autores marxistas são notáveis (entre outros, Santos, 2007). Um debate relacionado, na ocasião, foi sobre a natureza das relações de trabalho existentes nas áreas rurais: seriam feudais ou disfarçadamente capitalistas? Moacir Palmeira analisou o assunto em sua famosa tese de doutoramento, nunca publicada (Palmeira, 1971).

Deve ser notado, en passant, que quase todos esses autores seriam igualmente "caiopradistas", em alusão a Caio Prado Junior, o influente autor marxista ligado ao antigo Partido Comunista Brasileiro. Seus estudos sobre o campo apontavam a existência de uma típica via capitalista de transformação então em curso, desta forma estabelecendo uma tradição ortodoxa de 
interpretação sobre os eventos e processos no campo brasileiro. Alguns de seus mais relevantes artigos sobre o assunto foram publicados antes do golpe militar de 1964 (Prado Junior, 1979) ${ }^{4}$.

Esta "visão agrária" (ou "agrarista") sobre as transformações no campo são relevantes sob um ponto de vista analítico, mas fogem aos objetivos do presente artigo. O Brasil erigiu em sua história uma das mais assimétricas distribuições da propriedade da terra em todo o mundo e, assim, a continuidade dessa estrutura estimulou numerosos estudos que denunciaram o acesso não democrático à terra, mas também - e particularmente - os seus impactos econômicos. A referência clássica sobre o tema foi Quatro séculos de latifúndio (1968), de Alberto Passos Guimarães. A literatura sobre a terra e sua concentração tem sido desde então discutida, em estudos cada vez mais refinados, com dados estatísticos que se tornaram mais precisos, como indicam alguns estudos (Hoffmann \& Ney, 2010). É um tanto bizarro, portanto, que mesmo que a partir de 1995 o programa de reforma agrária tenha transferido aproximadamente 90 milhões de hectares (três vezes a área total da Itália) para quase um milhão de novos assentados, esse desempenho quantitativo notável não tenha alterado o índice de Gini relativo à concentração da terra.

O então influente tema da redistribuição da terra foi gradualmente se tornando marginal - do ponto de vista social e político - em face da urbanização e da impressionante transformação da produção e da produtividade, especialmente no presente século. Quando se atenta para o fato de estar em curso uma rarefação demográfica que reduz a população rural em todo o campo brasileiro, a qual corrói a demanda social pela reforma agrária, uma conclusão inevitável é que a estrutura de propriedade da terra permanecerá concentrada, talvez para sempre. Ainda assim, a literatura sobre "o peso da terra nas mãos de poucos", propagada por intelectuais ou comentaristas politicamente motivados levou à persistência do "eixo agrarista" na literatura sobre o rural no Brasil. Combinando a distribuição desigual da

\footnotetext{
São também relevantes as contribuições de Ignácio Rangel, entre 1950 e os anos 1970. Suas análises, com frequência, discutiram os temas rurais, como a estrutura da propriedade e a reforma agrária. Foram reflexões originais e emblemáticas manifestações de Economia Política, representando leituras heterodoxas e, por isso, muitas vezes controversas. Deixou vasta produção científica que pode ser aferida em Rangel (2005) e Jabbour (2017).
}

terra com as incontáveis formas de iniquidade social que sempre tipificaram o cotidiano nas áreas rurais (especialmente a inexistência de direitos legais, até recentemente), essas leituras agraristas se mantiveram presentes, ainda que estejam perdendo sua visibilidade no atual século.

O segundo foco de interesse até os anos 1960 e parte da década seguinte, especialmente entre os economistas, foi "o estreito limite dos mercados domésticos". Em outras palavras, uma perspectiva que alertava sobre a inviável expansão do capitalismo (via industrialização) em função da reduzida massa de consumidores existente. Era assim porque a maioria dos brasileiros residia no campo, ou vivendo com salários aviltantes ou, então, produzindo, em especial, os alimentos para a sua própria subsistência. Curiosamente, esta visão convergia para a primeira, porque a maioria desses autores argumentava que o obstáculo estrutural somente seria ultrapassado com uma política massiva de reforma agrária. Foi, portanto, um curioso período em que pesquisadores e estudiosos conservadores compartilharam a mesma interpretação de marxistas, os quais também defendiam a mesma política, ainda que sob outras justificativas, como "desenvolver as forças produtivas para vencer as contradições do capitalismo". Na história intelectual dos cientistas sociais que estudaram o campo, o primeiro modelo de interpretação ("agrarista") mobilizou, em especial, os sociólogos e os antropólogos, assim como os economistas marxistas. Já a segunda visão aqui referida ("agrícola") engajou principalmente os economistas neoclássicos.

Um notável artigo de Antônio Barros de Castro sintetizou na ocasião essas vias de interpretação então existentes. Trata-se de artigo publicado em seu famoso livro, Sete ensaios sobre a economia brasileira (1969). Embora relativamente breve, o Capítulo 2 do livro, intitulado "Agricultura e desenvolvimento no Brasil", é uma iluminadora introdução a esta disputa analítica. A primeira parte do artigo discute as " posições divergentes", enquanto a segunda parte discutiu as "funções da agricultura" e seu desempenho no caso brasileiro (Castro, 1969, p. 79-146). Castro já apontava as dificuldades analíticas para explicar o desenvolvimento agrário, alertando para "a natureza sem precedentes de nossos problemas na agricultura". O autor indicou que até então a agricultura não desenvolvera "obstáculos para a industrialização brasileira", e concluiu que as avaliações 
críticas - em particular aquelas de autores marxistas que propunham a reforma agrária - eram ou "erradas ou não eram críticas à agricultura, mas, antes, derivadas do sistema socioeconômico sob o qual vivemos" (Castro, 1969, p. 79). Ignácio Rangel, um conhecido economista marxista e que escreveu copiosamente sobre aqueles anos iniciais, reconheceria esse pecado original das análises à esquerda:

Contrariamente ao que nós, os revolucionários de 1930, acreditávamos, a industrialização do Brasil seria possível, mesmo sem a reforma agrária - no sentido de transformar grandes propriedades em pequenas propriedades familiares. A via Prussiana ou Junker, mutatis mutandis, a qual substitui a velha grande propriedade feudal na grande empresa rural capitalista de larga escala, não apenas permitiu a industrialização do país, mas também ofereceu a esta dita industrialização um extraordinário empurrão (Rangel, 1988, p. 3).

Em síntese, durante o período imediatamente precedente a 1970, a literatura sobre "o rural" apresentava algumas facetas típicas. Por exemplo, era pobre do ponto de vista empírico. E era assim porque ainda se privilegiavam leituras mais especulativas. Havia a ambição de "analisar o Brasil", sem existirem então evidências estatísticas rigorosas para atender esse objetivo grandioso. Como resultado, diversos autores influentes ofereceram conclusões que o tempo demonstrou serem equivocadas. Adicionalmente, os sistemas de dados, como os censos, não eram suficientemente abrangentes para extrair sólidas conclusões. Finalmente, a comunidade de estudiosos era reduzida e não tinha formação científica adequada para conduzir pesquisas rigorosas, prevalecendo ainda escolhas, muitas vezes, flagrantemente ideológicas, na acepção mais aceita do termo.

Um aspecto curioso daqueles anos deve-se às frequentes generalizações indevidas. Muitas interpretações e conclusões que se apresentavam como "nacionais" eram, de fato, regionais e, comumente, específicas de situações sociais e econômicas de São Paulo, o único estado que já estabelecera atividades acadêmicas e de pesquisa robustas. Desta forma, trabalhos sobre "o País", significando o Brasil rural como um todo, eram, de fato, análises de processos sociais rurais em São Paulo, com as conclusões sendo generalizadas para o restante do País. O comentário não é um exagero e nem uma crítica ligeira e apressada, pois desde os anos 1950 surgiram extraordinárias atividades de pesquisa na Universidade de São Paulo dirigidas aos processos sociais rurais. Entre elas, a formação do Centro de Estudos Rurais e Urbanos, dirigido durante muitos anos por uma das fundadoras da Sociologia Rural no Brasil, Maria Isaura Pereira de Queiróz ${ }^{5}$.

Como ilustração desse vezo relativo à equivocada generalização, cite-se o livro de Maria Conceição D'Incao e Mello, O bóia-fria, acumulação e miséria (1975), resultante de sua tese de doutorado, cujos levantamentos empíricos foram realizados nas regiões rurais da Alta Sorocabana. A pesquisa dedicou-se a entender a emergência do trabalho temporário que passou a ser intitulado de "boiafria", o qual decorreria da culminação de um processo de exploração do trabalho humano. De acordo com a autora, o crescimento

das relações de produção nas áreas rurais resultante da expansão da agricultura comercial, às expensas da agricultura de subsistência é acompanhado, de um lado, pela substituição de formas de exploração da força de trabalho com remuneração total ou parcial in natura (arrendatários, parceiros, posseiros) pela remuneração monetária (assalariados rurais) (Mello, 1975, p. 148).

O livro recebeu generalizada aclamação, embora acrítica, e suas conclusões foram apontadas como uma "tendência irreversível" que logo transformaria rapidamente o campo brasileiro ${ }^{6}$.

Esses avanços (ou bloqueios, por outro ângulo de análise) se tornaram nítidos no final da década de 1960, antes de ser iniciada outra fase, inicialmente simultânea com os anos de expansão econômica chamados de "milagre brasileiro". O livro que simbolicamente marcou o nascimento desse novo capítulo sobre os processos sociais e econômicos materializados nas regiões rurais foi Vida rural e mudança social (1972). A publicação incluía alguns famosos artigos de autores estrangeiros e, na segunda parte, nove artigos dos mais importantes

5 Sobre essas considerações, examine-se o estudo pioneiro intitulado "Sociologia no Brasil" (1956), de Antônio Cândido. O estudo descreve inúmeras atividades em São Paulo no campo da Sociologia dedicada aos processos sociais rurais (Cândido, 2006).

6 Embora de impacto reduzido, outro exemplo de generalização excessiva e inapropriada, centrada em determinadas regiões rurais de São Paulo, mas sugeridas para todo o País, foi a tese de doutoramento de um influente autor, José Graziano da Silva, depois transformada em livro (Silva, 1981a). Em sua pesquisa, também sugeriu que a emergência do trabalho temporário logo se estenderia para o restante da agricultura empresarial brasileira. 
cientistas sociais brasileiros que escreveram sobre o assunto (Szmrecsányi \& Queda, 1972).

Pelo ângulo da Economia Política, é também relevante referir-se a um relatório de pesquisa que, de fato, representou a "transição" entre essas duas fases e produziu significativa repercussão. Foi pesquisa realizada em algumas regiões por um experimentado grupo de pesquisadores que pretendia explicar "o Brasil rural". Trata-se de Posse e uso da terra e desenvolvimento socioeconômico do setor agrícola (1966), esforço multidisciplinar que pesquisou algumas situações regionais, utilizando um arsenal de armas metodológicas então oferecidas pelas Ciências Sociais. O documento também foi capaz de alertar para os problemas sociais e econômicos causados pela concentração da terra e, assim, reagia à revolução cubana, tentando propor reformas que pudessem evitar revoltas sociais nas áreas rurais (Cida, 1966).

\section{Os anos dourados}

$\mathrm{O}$ período mais exuberante de estudos rurais no Brasil provavelmente floresceu entre a metade dos anos 1970 e a segunda metade dos anos 1990, cobrindo, assim, aproximadamente duas décadas. Vistos em retrospecto, foram os anos mais promissores das Ciências Sociais dedicadas aos temas rurais. Poderá parecer paradoxal, porque se esperaria sempre uma evolução contínua e cumulativa do conhecimento e da capacidade de análise sobre os processos sociais rurais depois daqueles anos, e entrando no atual século. Não tem sido assim, no entanto, como se discute a seguir.

As razões que explicam porque essas atividades prosperaram nesse segundo período citado são relativamente fáceis de identificação. Primeiramente, o "peso rural" era ainda muito expressivo na consciência social dos brasileiros e, assim, atraía muitos estudiosos. Era inevitável que os pesquisadores da época, sobretudo os iniciantes, selecionassem o "mundo rural" como o ponto de partida para suas respectivas carreiras acadêmicas. Grosso modo, apenas uma década mais tarde é que alguns desses cientistas sociais mudaram seus interesses e migraram para outros campos temáticos.

Alguns exemplos merecem ser citados. Entre os sociólogos, Juarez Rubens Brandão Lopes, autor de Do latifúndio à empresa. Unidade e diversidade do capitalismo no campo (Lopes, 1981), também autor de um brilhante artigo sobre a expansão capitalista no campo paulista, publicado na lendária revista Estudos Cebrap (Lopes, 1978). No artigo, pioneiramente deixou a retórica usual do discurso marxista e calculou um indicador empírico para estimar a taxa de mais-valia correspondente à emergência da agricultura capitalista. Maria Rita Loureiro foi igualmente influente com os seus livros sobre "a pequena produção", também em São Paulo (Loureiro, 1977, 1987). Outro livro referencial foi Os colonos do vinho, de José Vicente Tavares dos Santos. Foi o primeiro esforço de aplicação do arsenal teórico chayanoviano em um caso concreto, iluminando a subordinação comercial de pequenos produtores ao complexo agroindustrial das regiões viticultoras do Rio Grande do Sul (Santos, 1978). Seu livro foi também a única tentativa, de fato, a introduzir Chayanov nas Ciências Sociais brasileiras e referências posteriores não demonstraram a mesma densidade explicativa.

Entre os economistas, mencionando especialistas de orientações teóricas distintas, pode-se fazer menção a Sérgio Silva (Silva, 1976, 1981b) e Geraldo Müller (1980, 1989), o último um relevante contribuinte ao debate sobre os "complexos agroindustriais" que emergiu na década de 1980. Cita-se também a contribuição de José Roberto Mendonça de Barros, um excepcional autor que posteriormente se afirmou como um dos mais importantes estudiosos da economia brasileira (Barros, 1983) ${ }^{7}$. Todos foram ativos nos estudos rurais, com significativa produção e influência intelectual, mas posteriormente migraram para outros campos temáticos de pesquisa.

A segunda razão que explica o crescimento desses estudos no período supracitado decorreu da institucionalização do campo das Ciências Sociais sobre "o rural", o que ocorreu durante os anos do "milagre brasileiro". Na década de 1970, os fundos para a pesquisa cresceram e as universidades federais abriram novas posições nesses campos de especialização. Da mesma forma, o treinamento em pós-graduação foi encorajado - especialmente no exterior, porque existiam

\footnotetext{
Outro autor referencial foi Fernando Homem de Melo, e seu livro O problema alimentar no Brasil: a importância dos desequilíbrios tecnológicos (Paz \& Terra, 1981) foi influente nos anos 1980. Também José Eli da Veiga foi outro pesquisador relevante, com vasta produção científica. Nos anos 1990, no entanto, Veiga passou a dedicar-se a um foco socioambiental, tópicos sobre o crescimento econômico e outros além do campo mais restrito do "rural" propriamente dito.
} 
raros cursos de mestrado e, praticamente, nenhum curso de doutoramento na área. No Rio de Janeiro, a criação dos cursos de pós-graduação em "Agricultura e Desenvolvimento" (CPDA) e em Antropologia Social no Museu Nacional foram fatos extremamente importantes. Esses cursos, que rapidamente recrutaram e treinaram dezenas de novos pesquisadores, receberam o crucial apoio da Fundação Ford. No caso do CPDA, foi um apoio que permitiu o nascimento de uma notável atividade acadêmica que durou do final dos anos 1970 e seguiuse durante uma boa parte da década seguinte. Foi o "Programa de Intercâmbio em Pesquisas Sociais sobre a Agricultura" (PIPSA), possivelmente o mais extraordinário momento na história intelectual dos estudos rurais no Brasil. Naqueles primeiros anos, os pesquisadores do CPDA conduziram o projeto "Evolução e estado atual da agricultura brasileira", o qual resultou, entre outros relatórios, em uma avaliação inédita sobre os debates que prevaleceram entre 1950 e 1970 (Castro, 1979). Sobre o Museu Nacional, o apoio financeiro da Ford tornou possível à instituição mobilizar uma das mais sólidas equipes de pesquisa já formadas. Inspirados pela Antropologia, o grupo produziu diversos estudos seminais (Garcia, 2003).

A terceira razão para explicar o crescimento dos estudos rurais naqueles anos foi provavelmente devido às mudanças políticas iniciadas em 1985, com o colapso do regime militar. Na época, vieram a lume com mais intensidade os deploráveis temas sociais desde sempre associados à história rural, como as formas de exploração social, pobreza, a ausência de direitos e a concentração da terra - e seu contrário, a reforma agrária. Esses temas vieram à superfície mais vigorosamente e puderam ser livremente debatidos com o processo de democratização. A nova Constituição de outubro de 1988 consagrou em suas metas diversas demandas sociais, sobretudo a reforma agrária e os direitos sociais legais nas regiões rurais. A "visão agrária" foi assim reforçada naquela conjuntura e reapareceu com mais vigor político e tornou-se assunto predominante na década seguinte e mesmo durante uma parte do presente século. No final da década de 1980, o Movimento dos Trabalhadores Rurais Sem Terra (MST), formalmente criado em 1983, já vinha ganhando amplitude política. Da mesma forma, a Confederação Nacional dos Trabalhadores na Agricultura (Contag) também tinha sido uma força política que difundira os mesmos temas desde a década de 1970. Naqueles anos, após o regime militar, formas organizacionais ligadas ao empresariado rural também emergiram e foram estudadas, quase solitariamente, por Regina Bruno, que publicou extraordinários trabalhos sobre essas novas formas organizacionais (Bruno, 1997).

No entanto, a mais decisiva razão que explicaria o renovado interesse de uma geração de cientistas sociais voltados aos estudos rurais foi a impressionante expansão da modernização da agricultura, desencadeada a partir do final da década de 1960, processo que se estendeu até à grave crise econômica do início dos anos oitenta (Martine \& Garcia, 1987; Delgado, 1985). Nesse período de explosivo crescimento da economia agropecuária, as perversas facetas sociais da história rural foram ignoradas, o que deu origem à expressão "modernização conservadora" (Silva, 1982). Em outras palavras, significou uma mudança capitalista nas regiões rurais sem alterar a estrutura de propriedade da terra, fato que enterrou a tese antes referida da "estreiteza do mercado interno" (que seria causada pela concentração da terra).

Não existe espaço nesse artigo para detalhar fatos ocorridos em tempos mais breves, quando um projeto original, um livro ou outros eventos disseminaram temporariamente um novo "subtema". Um exemplo foram as pesquisas de Carneiro (1998) e Schneider (2003). Estes estudos que demonstraram a crescente magnitude de trabalho não agrícola articulado às cadeias produtivas. Foi discussão oportuna, porque ofereceram evidências sobre um setor econômico que se transformava, diversificando a sua estrutura interna.

Mas é necessário também realçar uma série de novas tendências, processos e mudanças que estavam em curso naqueles anos citados.

Em face da degradação dos recursos naturais, decorrente do processo de modernização dos anos 1970, a "dimensão ambiental" emergiu como um dos mais sedutores temas e, ao longo da década seguinte, despertou crescente interesse. Assim, um livro referencial foi A questão agrária e ecologia, de Francisco Graziano Neto, o qual, desde então, tem sido um ativo analista sobre os assuntos rurais no Brasil (Graziano Neto, 1982). Especialmente a partir dos anos 1990, os tópicos ambientais se tornaram um eixo permanente de disputas sociais e vêm sendo estudados amiudadamente, em particular a partir de uma perspectiva multidisciplinar.

Inúmeras ilustrações emblemáticas desta fase podem ser citadas, não sendo possível estender-se 
em demasia, quatro situações específicas são aqui referidas. Primeiramente, talvez o mais fascinante de todos os possíveis exemplos, do ponto de vista de sua complexidade teórica e sofisticação argumentativa, o qual gerou intenso debate, diz respeito ao tema do "locus social da pequena produção no capitalismo" ${ }^{8}$. Esse é desafio analítico que apresenta distantes raízes históricas, pois remonta às origens das disciplinas que estudaram o tema. No caso brasileiro, uma possível gênese estaria relacionada às controvérsias marxistas dos anos sessenta, mas três autores poderiam ser citados nesta nova fase. Francisco Sá Jr, que discutiu o papel da agricultura empobrecida no Nordeste rural (Sá Júnior, 1973); José de Souza Martins, que investigou o lugar da agricultura familiar e suas relações com a modernização agrícola em São Paulo (Martins, 1975), e, especialmente, o famoso artigo de Francisco de Oliveira, "A economia brasileira: crítica à razão dualista" (Oliveira, 1972).

Esses autores, cada um seguindo orientação teórica específica, discutiram o argumento cepalino que desde a década de 1950 vinha defendendo uma visão dualista para explicar o subdesenvolvimento na América Latina. Os três autores argumentaram que, pelo contrário, existiria uma "relação umbilical" entre as manifestações de pobreza de baixa ou nenhuma mercantilização, o seu modo de produção agrícola e, de outro lado, a dinâmica econômica. Simplificadamente: existiria uma relação direta entre pobreza rural e a produção de alimentos baratos e o processo mais geral de expansão capitalista, pois os produtos alimentares eram primariamente destinados à reprodução social das famílias rurais pobres. E esse objetivo os ligava diretamente ao processo de acumulação de capital, pois alimentos baratos garantiriam baixos salários nas cidades. Ao fazê-lo, contudo, os autores incorreram na ira de seus críticos, que os qualificaram de portadores de uma visão "funcionalista" das relações

8 É entristecedor verificar que o debate nacional no campo dos estudos rurais usualmente ignora os debates internacionais, especialmente aqueles em desenvolvimento nos países de língua inglesa. Foi o caso, por exemplo, da ampla literatura inspirada no aclamado artigo de Susan Mann e Charles Dickinson, originalmente publicado em 1978. Dez anos depois foi publicado em português (Mann \& Dickinson, 1987), sem gerar nenhuma repercussão. Provavelmente, a dominante ortodoxia marxista nos estudos rurais brasileiros tenha tacitamente vetado a discussão sobre as ideias propostas por aqueles autores sobre o desenvolvimento capitalista na agricultura. entre o desenvolvimento agrário e a expansão econômica, um debate que durou até a metade da década de 1980.

Na virada dos anos 1970, uma iniciativa relevante foi o projeto internacional "Multinacionais e agricultura", coordenado de Paris por Gonzalo Arroyo. Mobilizou diversos pesquisadores latino-americanos, tendo desenvolvido uma alternativa ao Marxismo ortodoxo, ainda que também inspirado na Economia Política mais à esquerda. Foi centrado em pesquisa empírica e investigou a intensa modernização agrícola em algumas regiões do País. Um grupo de estudiosos brasileiros esteve envolvido e suas análises ao final ofereceram um novo modelo explicativo para além da forte ortodoxia marxista então dominante - o chamado paradigma "agroindustrial". Posteriormente se tornou um arcabouço igualmente ancorado no institucionalismo econômico (e suas variantes posteriores). E entendia os pequenos produtores como potencialmente virtuosos integrantes dos processos de expansão capitalista no campo, em oposição aos argumentos então estabelecidos sobre a "proletarização inevitável" defendida pelos círculos à esquerda convencionais. Dois exemplos desses estudos foram publicados por Bernardo Sorj (Sorj, 1980) e Geraldo Müller (Müller, 1989). John Wilkinson escreveu Estado, agroindústria e a pequena produção, um iluminador livro no qual sintetizou essas discussões teóricas (Wilkinson, 1986, p. 11-86). Em consequência, dicotomias então influentes, como "rural versus urbano", "mercados domésticos versus exportações" ou a "histórica necessidade" da reforma agrária se tornaram parcialmente obsoletas após o surgimento desse novo arcabouço teórico.

Entretanto, talvez tenha sido a tese de doutoramento de Guilherme Delgado que, de fato, animou uma nova onda de estudos na segunda parte dos anos 1980, estimulando diversos projetos relacionados aos temas que discutira em sua tese. Delgado propôs uma inovadora análise econômica sobre o crescimento da agricultura e suas transformações durante a década de 1970. Foi um dos primeiros autores a examinar o papel dominante desempenhado pelo capital financeiro. Sua análise marxista foi publicada na forma de livro em 1985 (Delgado, 1985). Foi seguido por outros autores que avançaram no passo seguinte lógico, que foi pesquisar as características dos complexos agroindustriais, em especial o projeto coletivo da Unicamp coordenado por José Graziano da Silva e Angela Kageyama (Müller, 1989; Kageyama, 1990). Contudo, esses esforços gradualmente 
perderam seu fôlego analítico e, no início dos anos 1990, foram relativamente marginalizados - com alguma surpresa, em face da importância de tais iniciativas de interpretação. Felizmente, os estudos sobre as cadeias produtivas não foram inteiramente interrompidos, mas experimentaram uma frutífera continuidade sob as iniciativas promovidas na Universidade de São Paulo, através do "Programa Pensa", sob o brilhantismo científico de Décio Zylbersztajn e Elizabeth Farina. Esse foi um programa que introduziu uma terceira via para analisar as relações entre a agricultura e a indústria, desta vez influenciada pelo modelo estabelecido em Harvard por Ray Goldberg, em 1955.

Em síntese: durante a década de 1980, três modelos disputavam a primazia das interpretações sobre as transformações econômicas e produtivas nas regiões rurais brasileiras. Dois deles se apresentavam à esquerda, um modelo seguindo o Marxismo ortodoxo e o segundo em novas contribuições então oferecidas pela Economia Política, fortemente empíricas e abertas a novos autores e teorias. A terceira via, centrada no "Pensa", vem desenvolvendo pesquisas de cadeias produtivas, analisando-as a partir de modelos inspirados na teoria original referida.

Outro momento especial, nesta segunda fase, foi o projeto "Caracterização do novo rural brasileiro, 1981/95" (Projeto Rurbano), também coordenado por José Graziano da Silva, o qual mobilizou um grande número de pesquisadores, oriundos de onze estados. O projeto pretendeu "(...) analisar as transformações observadas nas relações rurais-urbanas no Brasil, iniciando-se em 1981 e fundando-se nos microdados das PNADs" (Silva, 1999, p. xii). O período principal estudado foi a década de 1990 e o projeto resultou em diversos artigos e livros, tentando identificar a formação de uma nova "ruralidade", supostamente emergindo em várias regiões. O autor destacou que esse novo momento histórico seria caracterizado pela expansão de uma "moderna agricultura" articulada às agroindústrias, mas também seria mantido um "setor de subsistência", cujo papel seria, em típico jargão marxista, manter "a relativa superpopulação e um exército de reserva de trabalhadores sem-terra nas regiões rurais" (Silva, 1999), assim ignorando a possibilidade de famílias rurais pobres abandonarem o campo - fato que vem sendo intensificado no presente século, ressalte-se de passagem.
Finalmente, em outro fato saliente, mas confinado, particularmente, ao labor dos sociólogos, o período também observou a proliferação de pesquisas sobre "assentamentos rurais". Com a gradual expansão do MST, das ocupações de terras privadas e da lenta formação de assentamentos rurais, inúmeros sociólogos, inspirados em leituras nitidamente ideologizadas das realidades rurais, tentaram perceber em seus trabalhos de campo a emergência de "formas de resistência" (ao capitalismo) que muitas das áreas reformadas estariam fermentando. Especialmente na década de 1990, esses trabalhos, quase sempre na forma de dissertações ou teses, cresceram quase exponencialmente. Foi um momento melancólico da Sociologia Rural, pois a vasta maioria dos estudos era acrítica, exaltando processos políticos que, de fato, não existiam. Embora de grande envergadura, em função do número de trabalhos realizados, o resultado final foi pobre no tocante à produção de conhecimento relevante.

Em arriscada simplificação retrospectiva, cobrindo os últimos 50 anos, síntese que impede salientar as exceções notáveis que certamente existem e marcaram esta fase, no geral a Sociologia dos processos sociais rurais optou majoritariamente, em sequência temporal, por diversas etapas orientadas, quase sempre, por opções ideológicas, das análises iniciais em torno da "necessidade da reforma agrária" para, posteriormente, os estudos, meramente descritivos, sobre assentamentos rurais e as lutas sociais no campo e, já nos anos noventa, para a exaltação mágica sobre "agricultura familiar". Mais recentemente, as opções desse campo disciplinar têm dirigido inúmeras iniciativas de pesquisa sob outro termo que, na realidade, é conceitualmente vazio: "agroecologia" (Navarro, 2013) ${ }^{9}$. Mas ressaltando que, em todas essas situações, os autores julgam perceber primordialmente possibilidades anticapitalistas. Embora ainda inexistente, uma "Sociologia da Sociologia Rural" certamente comprovaria, talvez facilmente, que tais relações empobrecem intensamente os resultados de pesquisa ${ }^{10}$.

9 Especialmente na década de 1980, seguindo uma tendência internacional, o campo dos "movimentos sociais" (ou o tema mais geral dos conflitos sociais) também atraiu diversos especialistas interessados em suas manifestações rurais. Uma autora referencial nesse campo tem sido Ilse Scherer-Warren (como um exemplo, consulte-se Scherer-Warren, 1989).

10 Salientando que há vários anos não existem mais sociólogos dedicados principalmente à investigação científica sobre os processos sociais rurais nas duas maiores e mais importantes universidades brasileiras (USP e Unicamp). 
Por fim, em menção à parte, até mesmo para citar uma notável exceção ao comentário anterior, é preciso destacar a carreira acadêmica de José de Souza Martins, o lendário sociólogo da USP e autor, provavelmente, da mais vasta produção científica entre seus pares da disciplina (37 livros publicados, em agosto de 2018). Trata-se, de fato, de uma trajetória excepcional que resultou em uma Sociologia "da sociedade brasileira", ainda que empiricamente focada, sobretudo, em ambientes rurais, na maior parte de suas pesquisas de campo. Tendo se incorporado àquela universidade no final dos anos 1960, esse autor tem desenvolvido produção prolífica há mais de 50 anos. Provavelmente, é o único sociólogo brasileiro que construiu uma inovadora teoria sociológica, mas apresentá-la, ainda que em seus contornos gerais, seria impossível no espaço desse artigo. Uma primeira aproximação à Sociologia de Martins pode ser encontrada no festschrift publicado recentemente (Frehse, 2018).

\section{Tendências recentes}

A produção das Ciências Sociais sobre temas rurais defronta-se com algumas características deformadoras que persistem no tempo, as quais têm sido contraproducentes à consolidação de resultados mais robustos. Do ponto de vista de suas disciplinas, por exemplo, as contribuições dos distintos campos científicos desse conjunto têm sido fortemente heterogêneas. É surpreendente que a Ciência Política, considerando-se o intenso impacto político das empobrecidas condições de vida no campo, não tenha se interessado em desenvolver pesquisas sobre processos políticos vigentes nessas regióes. Profissionais de ofício dessa disciplina, de fato, apenas raramente pesquisaram o campo brasileiro e sempre sem nenhuma continuidade ${ }^{11}$.

Outra consequência da ausência desses especialistas interessados em pesquisar processos políticos é que essas dimensões têm sido estudadas menos como

\footnotetext{
11 Nas duas décadas mais recentes, surgiram diversas iniciativas para estudar "políticas públicas". Embora uma generalização arriscada, talvez seja correto enfatizar que a vasta maioria desses esforços produzem, sobretudo, descrições, mas não análises propriamente ditas dessas políticas. Esta insuficiência ocorre porque são frágeis os estudos sobre o Estado e sua evolução e natureza. Sem esta compreensão, a interpretação dessas políticas é uma impossibilidade lógica.
}

categorias ancoradas nas tradições teóricas da disciplina e, mais frequentemente, como "desejos" ou escolhas (políticas) dos autores, especialmente em trabalhos de sociólogos, ensejando interpretações mais militantes do que propriamente científicas. Esta, na realidade, é outra característica nociva desse último e recente período, que se estende, particularmente, no presente século - a nítida partidarização da vida universitária e da pesquisa no grande campo de "Humanidades", o que tem causado visíveis prejuízos à qualidade da pesquisa. Essa faceta é evidente, em especial, no campo da Sociologia, uma disciplina que vem sendo afetada gravemente por posturas nitidamente ideológicas.

Já a Antropologia, após um espetacular e florescente período citado na seção anterior, quase sempre sob a inspiração de pesquisadores ligados ao Museu Nacional, parece também nesse século ir perdendo fôlego ou, então, se dirigindo a outros focos temáticos distanciados dos contextos rurais. Ressalta-se que a maioria das pesquisas antes realizadas pelos antropólogos do museu concentrou-se em contextos do Nordeste rural. Apenas muito raramente pesquisas no âmbito desta disciplina ocorreram em outras regiões - como exemplo, os livros de Margarida Maria Moura, com pesquisas de campo realizadas no centro do país (Moura, 1978, 1988).

Por fim, restaria um comentário sucinto sobre as contribuições da Economia, a qual, pelo contrário, vem apresentando evolução distinta das demais disciplinas referidas. Em termos genéricos, as pesquisas em Economia sobre os processos rurais, nos últimos 50 anos, seguiram uma trajetória específica. Na década de 1970 dominavam as perspectivas teóricas influenciadas ou pelo marxismo ortodoxo ou, então, por uma visão estruturalista inspirada na tradição da Cepal. Era então diminuta e menos influente a produção de economistas neoclássicos, circunscrita, contudo, em um círculo influente de pesquisadores associados em torno da então Sociedade Brasileira de Economia Rural ${ }^{12}$. Em consequência, se a disciplina fosse "vista do alto", se perceberiam, de um lado, amplas "narrativas históricas", como seria a preferência dos primeiros autores e, de outro lado, a quase inexistência de métodos quantitativos, como seria o apanágio da escola neoclássica.

12 Como um exemplo de análises tipicamente neoclássicas, sugere-se consultar a vasta produção científica de Eliseu Alves (por exemplo, Alves, 2006). 
Mas a expansão de cursos e o crescimento das atividades de pesquisa, posteriormente, de um lado, e também o crescimento da economia agropecuária, de outro lado, lentamente modificaram essa distribuição de orientações teóricas.

Nos anos de expansão recente, modelos teóricos de Economia mainstream gradualmente se tornaram mais presentes e foram consolidando posições nas diversas instituições do País, lentamente marginalizando uma visão estruturalista (em seus diversos matizes) e, sobretudo, acuando fortemente a tradição marxista. Após 1989, com a queda do Muro, mas especialmente no início do presente século, com o espetacular crescimento da economia agropecuária (Navarro \& Buainain, 2017), visões neoclássicas (ou variantes recentes de escolas teóricas próximas) se tornaram hegemônicas, inclusive com a formação de diversos cursos de pós-graduação em "agronegócio". Essas parecem ser tendências irreversíveis no campo da Economia dedicada aos assuntos rurais. Ressalta-se, em correspondência à correta avaliação dos fatos, que esta reversão na influência das escolas de pensamento econômico dominantes deve-se também à trajetória e às relevantes contribuições das áreas de Economia Rural desenvolvidas na Universidade Federal de Viçosa, na Universidade de São Paulo (a Esalq, em Piracicaba, sob a liderança de Geraldo Sant'Ana Barros e Joaquim Bento de Souza Filho) e também a mesma área na Fundação Getúlio Vargas, no Rio de Janeiro - em particular a excepcional contribuição de Mauro de Rezende Lopes e Ignez Vidigal Lopes. Contudo, outra instituição de pesquisas importante, o Ipea, que no passado realizou estudos de grande relevância, sobretudo em Economia (com os importantes trabalhos de José Garcia Gasques, Guilherme Delgado e Gervásio Castro de Rezende), atua contrariamente, pois vem marginalizando os projetos de investigação com ocorrência empírica nas áreas rurais.

Uma demonstração empírica dessas tendências pode ser encontrada nos diversos artigos da mais longeva e relevante revista científica brasileira dedicada à Economia Rural, cuja publicação inicial intitulou-se "Revista de Economia Rural". Posteriormente a publicação se tornou multidisciplinar. O primeiro número teria vindo a lume em 1960, mas é provável que até 1967 os números tenham sido produzidos de forma mais rudimentar e com distribuição irregular, pois não foram encontrados nas bibliotecas pesquisadas, em Brasília. Além disso, o número de junho de 1968, curiosamente, é apresentado oficialmente o número 1 do primeiro volume. Em 1988, passou a intitular-se "Revista de Economia Rural e Sociologia Rural" e é a publicação oficial da Sociedade Brasileira de Economia Rural, uma das mais antigas organizações científicas do País, fundada em fevereiro de 1959.

Foram examinados praticamente todos os artigos principais publicados em cada número da coleção, totalizando 1.490 artigos (excluídos apenas os comentários curtos, notas e ocasionais resenhas). O exame desse significativo acervo permitiu algumas conclusões, ainda que preliminares. Em especial, se os textos publicados (e seus argumentos) representam as práticas dos economistas agrícolas associados à Sociedade, ou a ela próximos, em termos de afinidade teórica, é notável a relação entre os modelos explicativos (e suas respectivas visões de mundo) e os processos políticos principais em curso na sociedade brasileira. Grosso modo, por esse ângulo, a história intelectual desse grupo de cientistas sociais situado na órbita da Sociedade talvez possa ser dividida em duas partes. A primeira, da fundação e até o fim do ciclo militar. E a segunda, com a democratização política do País, a partir de meados da década de 1980.

Na primeira fase, durante o ciclo militar, são pesquisadores que estudaram os temas econômicos exclusivamente através de um modelo teórico afirmador da ordem social - o paradigma neoclássico. Em consequência, nenhum autor publicado na revista, nos números publicados nesta primeira fase, poderia ser enquadrado entre a corrente "agrarista" antes citada. Não significando que diversos artigos publicados não fossem "abrangentes", procurando interpretar esse ou aquele fenômeno a partir de uma ótica nacional. Mas as críticas contumazes da perspectiva agrarista sobre a concentração da terra, os salários rurais irrisórios, a precariedade da vida social no campo e, em especial, a inexistência de direitos nessas regiões, jamais fizeram parte dos artigos desta fase. Emblemático, por exemplo, foi o número especial 3, volume 16, publicado em 1978 e intitulado "Política agrícola e agricultura de baixa renda". Nele, o pioneiro da Economia Agrícola no Brasil, Ruy Miller Paiva, se pergunta - "por que a pobreza rural existe?". Sua resposta não poderia ser mais ilustrativa do entranhado conservadorismo da economia neoclássica, respondendo que existe porque “os preços não se mantém em níveis favoráveis aos 
produtores [e] os preços dos 'fatores tradicionais' (terra e mão de obra) atuam contra a adoção de técnicas modernas" (p. 42).

Com a democratização, a revista, a partir de meados dos anos 1980, iria se tornando gradualmente mais aberta a outros enfoques e, a partir da década seguinte, o modelo neoclássico passou a conviver com as mais diferentes abordagens explicativas, o que vem marcando a trajetória da publicação desde aqueles anos. Embora um curto artigo, a análise de Amílcar Baiardi sobre a Sociedade e sua produção científica espelhada na revista é exemplar, demonstrando, sobretudo, uma trajetória analítica admiravelmente correspondente à história política do país, em suas limitações e possibilidades (Baiardi, 2007).

Como resultado, examinando-se as disciplinas das Ciências Sociais e suas particularidades no Brasil, nesse meio século, é provável que esteja sendo observado um gradual decréscimo de interesse por parte das disciplinas mais diretamente motivadas por "temas sociais e culturais" (a Sociologia e a Antropologia). O esvaziamento populacional rural, o arrefecimento político sobre a "questão agrária", o virtual fim da reforma agrária e de movimentos sociais rurais reduziram drasticamente os objetos de análise preferenciais dessas disciplinas. A Economia também viu diminuir o seu interesse por esses mesmos temas, como foi no passado, e vem se concentrando, com predominância, em assuntos exclusivamente econômico-financeiros e produtivo-tecnológicos. Ou seja, curiosamente invertendo as relações entre as escolas de pensamento econômico, quando comparados os anos setenta e a situação atual. Atualmente a Economia neoclássica e suas variantes atuais parecem destinadas a consagrar-se como o único veio explicativo, conforme antes referido.

E, finalmente, a Ciência Política, que jamais esteve presente nesse campo de estudos, mantém-se desinteressada pelo mundo rural. Ressaltando, da mesma forma, que as pesquisas típicas da História também raramente foram atraídas pelo "rural" do último meio século. Em consequência, as leituras históricas estiveram presentes, mas através dos esforços dos demais cientistas sociais por exemplo, os trabalhos de um brilhante economista, Edmar Bacha, sobre a cafeicultura (Bacha, 2012) e de um renomado sociólogo, José de Souza Martins, sobre diversos momentos da história rural, exemplificados em seu clássico estudo sobre o colonato paulista (ver, como exemplo, Martins, 1979).

Em face do curto comentário acima, é inevitável concluir que a produção científica desse campo multidisciplinar sobre os processos sociais rurais tem sido marcada por fragmentação e irregularidade. Apenas excepcionalmente os esforços de pesquisa tem se mantido por mais tempo, procurando sedimentar conhecimentos cumulativos a partir de pesquisas sequenciais. No geral, tem ocorrido exatamente o oposto, com os pesquisadores variando erraticamente seus temas preferenciais de estudo e pesquisa ao longo do tempo.

Mas há outros fatores contribuintes que também afetam o desempenho geral. Os cientistas sociais brasileiros, em sua maioria, são apenas parcialmente atentos à bibliografia e aos debates internacionais e, até mesmo, com surpresa, há insuficiente reflexão sobre os textos dos próprios colegas brasileiros. Livros que foram demarcadores na literatura, como From Farming to Biotechnology. A Theory of Agro-industrial Development (Goodman et al., 1987), que teve até a tradução em português (1990) e seus três autores têm ligações diretas com os temas rurais brasileiros ${ }^{13}$; State and Countryside. Development Policy and Agrarian Politics in Latin America (Johns Hopkins University Press), de Merilee Grindle (1986), ou então The Agrarian Question and Reformism in Latin America (Johns Hopkins University Press), do influente Alain de Janvry (1981), exerceram escassíssima repercussão entre os autores brasileiros. Muitas vezes foram até desqualificados in limine, como foi o caso do primeiro livro referido acima, rapidamente classificado como mera manifestação de "reducionismo tecnológico" (Silva, 1992).

Ainda mais chocante, nem mesmo publicações referenciais de brasileiros produziram o debate que seria esperado. Como ilustração, mencionem-se dois livros. Primeiramente, $\mathrm{O}$ desenvolvimento agrícola. Uma visão

13 David Goodman foi o dirigente principal da Fundação Ford entre o final dos anos 1970 e até meados da década seguinte. É autor de importantes análises sobre o desenvolvimento agrário brasileiro (Goodman, 1977, 1981). Posteriormente, em Londres e depois na Universidade da Califórnia, se tornou um autor de vasta produção internacional. Bernardo Sorj é um peruano radicado no Brasil desde a sua juventude e um dos raros cientistas políticos com produção científica sobre os temas rurais, embora de curta duração (Sorj, 1980). John Wilkinson é um sociólogo inglês igualmente radicado no País, desde a conclusão de seu doutoramento, também um autor de importante produção científica (Wilkinson, 1986, 2008). 
histórica (1991), de José Eli da Veiga, um brilhante estudo comparativo sobre várias experiências nacionais, nas quais prosperou a chamada "agricultura familiar" e o autor disseca as razões que explicam a emergência de agriculturas que privilegiaram a administração familiar dos estabelecimentos rurais. Logo depois, o livro Paradigmas do capitalismo agrário em questão, de Ricardo Abramovay, publicado em 1992, ofereceu uma análise que trouxe conhecimento novo de imensa relevância para as Ciências Sociais (Abramovay, 1992). A repercussão desses livros foi pequena, gerando comentários mais superficiais, mas não a leitura atenta e suas consequentes reflexões analíticas. Em particular o livro de Abramovay, se fosse devidamente estudado, necessariamente representaria um turning point teórico para sustentar análises mais criativas sobre o desenvolvimento agrário brasileiro. Como foram publicações que, no entanto, problematizaram as teorizações clássicas do marxismo, ambos foram bloqueados elegantemente no campo da Sociologia e entre os cientistas sociais de orientação mais à esquerda.

Por fim, as transformações produtivas nesse século introduziram um fato novo e urgente, que é a necessidade de interpretar o desenvolvimento agrário como "uma totalidade". Diferentes tendências e processos, da unificação do mercado de trabalho rural entre as diversas regiões, e também entre o campo e os mercados de trabalho urbanos; as novas formas destinadas a viabilizar investimentos para a agropecuária, garantindo a contínua elevação da produtividade; a participação de novas firmas, inclusive internacionais, no setor, agora globalizado; a recente redução na oferta de trabalho; as dificuldades que parecem estar surgindo, em algumas regióes, com o manejo de recursos hídricos, entre tantos outros desafios, essas são algumas indicações empíricas que apontam a necessidade da interpretação sobre "o todo". A tradição de estudos regionalizados, setoriais ou particulares, que sempre foi a faceta principal nesse campo de pesquisa, talvez seja inapropriada no novo período. Desta forma, são fatos que começam a estimular as primeiras tentativas para analisar a agropecuária a partir de sua totalidade. O recente estudo de Fábio Chaddad foi pioneiro nesta direção, destinado a analisar sob um olhar abrangente as formas de empreendedorismo e a organização de cadeias de valor, incluindo da mesma forma os diferentes tipos de organizações de produtores. Foi estudo que se concentrou em regiões mais dinâmicas da economia agropecuária, em especial a relação entre os estados sulistas e o Centro-Oeste, onde atualmente se desenvolve uma parte expressiva da produção (Chaddad, 2016).

Movido por esta preocupação, menciona-se, em especial, o recente esforço de pesquisa, já no presente século, envolvendo inúmeros autores. Trata-se do "projeto sete teses", assim chamado porque seu ponto de partida foi o artigo publicado em 2013 (Buainain et al., 2013). Foi esse texto que propôs uma radical releitura sobre o desenvolvimento agrário brasileiro e, sobre ele, desenvolveu-se um amplo projeto de pesquisa que gerou, já no ano seguinte, a coletânea $O$ mundo rural no Brasil do século 21 (Buainain et al., 2014). São textos que propõem renovar com desenvoltura uma interpretação do Brasil rural como uma totalidade (e não apenas suas partes constituintes), a partir do pressuposto básico de ter ocorrido, nos últimos 20 anos, uma mudança profunda do padrão de acumulação na agropecuária, setor que vem crescentemente sendo determinado por formas do capital financeiro. Como se trata de análise relativamente recente, as diversas teses submetidas pelos autores apenas começam a ser discutidas entre os cientistas sociais brasileiros.

Analisadas essas tendências em seu conjunto, e retornando às considerações iniciais, é inevitável concluir que a "batalha de ideias e argumentos" encontrou curiosa evolução, opondo duas leituras opostas sobre o desenvolvimento do capitalismo no campo brasileiro e, no âmbito desta transformação, o papel da agropecuária e o futuro da vida social rural. Uma interpretação reformista, intitulada de "agrarista", envolvendo visões teóricas articuladas ao estruturalismo e o Marxismo (ou, lato sensu, à Economia Política) e que, entre os cientistas sociais, mobilizou em especial os sociólogos e antropólogos, também contando com parte dos economistas situados politicamente à esquerda, foi dominante por longo período, nesse meio século. À luz da trágica história rural brasileira, mobilizou mais recursos de pesquisa e produção de conhecimento para comandar a maior parte dos esforços intelectuais destinados a interpretar o desenvolvimento agrário - foi a visão mais influente até o final do século passado. Mas o crescimento da economia agropecuária, enraizado durante a década de 1970 e depois crescendo lentamente, encontrou vigorosa expansão no presente século e, em consequência, uma visão "econômica" passou a ser, recentemente, mais forte e dominante. Não parece existir mais lugar, em face 
desta inversão, para a perspectiva agrarista do passado e, assim, a disputa de ideias e argumentos das últimas cinco décadas pode estar chegando ao seu epílogo.

\section{Conclusões}

Cinquenta anos de continuado crescimento do setor agropecuário e, mais recentemente, a emergência do Brasil como uma das mais importantes potências produtoras de alimentos, não conseguiram estabelecer no país um conjunto sólido de agendas de pesquisa organizadas por alguma lógica consistente. Considerando os diferentes campos das Ciências Sociais, são trajetórias intelectuais, no geral erráticas e fragmentadas, afetadas por conjunturas políticas, modismos internacionais ou escolhas pessoais dos pesquisadores que refletem às vezes particularidades teóricas distanciadas do mundo real da produção e da vida social das regiões rurais. Adicionalmente, as disciplinas formadoras das Ciências Sociais vêm contribuindo de forma heterogênea para a produção de conhecimento relevante sobre os processos sociais rurais. A Ciência Política, em termos práticos, quase nada contribuiu para esse campo de pesquisa, enquanto a Sociologia, no geral, tem sido caudatária, sobretudo, de influências ideológicas, aderindo facilmente a iniciativas com pouca sustentação científica. Desta forma, o resultado geral dos esforços dos cientistas sociais tem avançado pontualmente em alguns subtemas, enquanto outros não encontram pesquisadores interessados.

Em face da significativa expansão do setor agropecuário no presente século, consolidam-se crescentemente os processos que poderão ser analisados pelos modelos econômicos e o fato, somado ao relativo esvaziamento demográfico do campo brasileiro, também estimula o desinteresse das demais disciplinas das Ciências Sociais. Como resultado, não será surpresa se no médio prazo a comunidade de pesquisadores, no Brasil, interessada nos processos sociais e econômicos em curso nas regiões rurais, cada vez mais, se restrinja aos economistas do establishment. Os temas propriamente sociais típicos da Sociologia, assim como os fenômenos culturais e os processos políticos que usualmente conformam os esforços de antropólogos e cientistas políticos, em magnitude crescente parecem estar deixando de mostrar ocorrência expressiva entre os interesses da pesquisa em curso no Brasil.

\section{Agradecimentos}

Registro meus agradecimentos sinceros a Alberto R. Cavalcanti, Alfredo Homma, Ana Louise Carvalho Fiúza, Anita Brumer, John Wilkinson e Ryan Nehring. Foram os leitores de uma versão preliminar do artigo e ofereceram valiosos comentários. Sou igualmente grato a dois avaliadores anônimos convidados pela revista e que ofereceram valiosos pareceres que aperfeiçoaram o texto final. Os erros remanescentes, contudo, são de inteira responsabilidade do autor. Registro meus agradecimentos sinceros a Alberto R. Cavalcanti, Alfredo Homma, Ana Louise Carvalho Fiúza, Anita Brumer, John Wilkinson e Ryan Nehring. Foram os leitores de uma versão preliminar do artigo e ofereceram valiosos comentários. Sou igualmente grato a dois avaliadores anônimos convidados pela revista e que oferecera $m$ valiosos pareceres que aperfeiçoaram o texto final. Os erros remanescentes, contudo, são de inteira responsabilidade do autor.

\section{Referências}

Abramovay, R. (1992). Paradigmas do capitalismo agrário em questão. São Paulo: Editora da Unicamp.

Alves, E. (2006). Migração rural-urbana, agricultura familiar e novas tecnologias (Coletânea de Artigos Revistos). Brasília: Embrapa.

Bacha, E. (2012). Política brasileira de café: uma avaliação centenária. In E. Bacha (Ed.), Belíndia 2.0. (pp. 305-408). Rio de Janeiro: Civilização Brasileira.

Baiardi, A. (2007). O pensamento econômico da sociedade brasileira de economia, administração e sociologia rural. In T. Szmrecsányi (Org.), Ensaios de história do pensamento econômico no Brasil contemporâneo (vol. 1, pp. 210-225). São Paulo: Ordem dos Economistas do Brasil.

Barros, J. R. M. (1983). A evolução recente da agricultura brasileira. In J. R. M. Barros (Ed.), Desenvolvimento da agricultura: estudos de casos. São Paulo: Pioneira.

Goodman, D., Sorj, B., \& Wilkinson, J. (1987). From farming to biotechnology: a theory of agro-industrial development. Oxford: Blackwell.

Bruno, R. A. (1997). Senhores da terra, senhores da guerra: a nova face politica das elites agroindustriais no Brasil. Rio de Janeiro: Forense Universitária, Editora da UFRRJ.

Buainain, A. M., Silveira, J. M., Alves, E., \& Navarro, Z. (2013). Sete teses sobre o mundo rural brasileiro. Política Agrícola, 22(2), 105-121. 
Buainain, A. M., Silveira, J. M., Alves, E., \& Navarro, Z. (2014). O mundo rural no Brasil do século 21: a formação de um novo padrão agrário e agrícola. Campinas: Unicamp.

Cândido, A. (1964). Os parceiros do Rio Bonito. Rio de Janeiro: José Olympio Editora.

Cândido, A. (2006). A sociologia no Brasil. Tempo Social, 18(1), 271-301.

Carneiro, M. J. (1998). Camponeses, agricultores e pluriatividade. Rio de Janeiro: Contracapa Livraria.

Castro, A. B. (1969). Sete ensaios sobre a economia brasileira. Rio de Janeiro: Forense.

Castro, A. C. (1979). Evolução recente e situação atual da agricultura brasileira (Coleção Estudos sobre o Desenvolvimento Agrícola, 7). Brasília: BINAGRI.

Chaddad, F. (2016). The economics and organization of brazilian agriculture. Londres: Academic Press.

Comitê Interamericano de Desenvolvimento Agrícola - CIDA. (1966). Posse e uso da terra e desenvolvimento sócioeconômico do setor agrícola. Washington: OEA.

Delgado, G. C. (1985). Capital financeiro e agricultura no Brasil 1965-1985. São Paulo: Ícone.

Faoro, R. (1958). Os donos do poder. Rio de Janeiro: Editora Globo.

Frehse, F. (2018). A sociologia enraizada de José de Souza Martins. São Paulo: Com-Arte.

Furtado, C. (1972). A estrutura agrária no subdesenvolvimento brasileiro. In C. Furtado. Análise do modelo brasileiro (pp. 91-120). Rio de Janeiro: Civilização Brasileira.

Garcia, A. (2003). A sociologia rural no Brasil: entre escravos do passado e parceiros do futuro. Sociologias, 5(10), 154-189.

Goodman, D. (1977). Rural structure, surplus mobilization, and modes of production in a peripheral region: The Brazilian Northeast. The Journal of Peasant Studies, 5(1), 3-32.

Goodman, D., \& Redclift, M. R. (1981). From peasant to proletariat: capitalist development and agrarian transition. Oxford: Blackwell.

Graziano Neto, F. (1982). Questão agrária e ecologia. São Paulo: Brasiliense.

Grindle, M. (1986). State and countryside: development policy and agrarian politics in Latin America. Baltimore: Johns Hopkins University Press.

Janvry, A. (1981). The agrarian question and reformism in Latin America. Baltimore: Johns Hopkins University Press.

Hoffmann, R., \& Ney, M. G. (2010). Evolução recente da estrutura fundiária e propriedade rural no Brasil. In J. G. Gasques, J. E. Vieira Filho, \& Z. Navarro. A agricultura brasileira: desempenho, desafios e perspectivas (pp. 45-66). Brasília: IPEA.
Jabbour, E. (2017). O marxismo e outras influências sobre o pensamento de Ignácio Rangel. Economia e Sociedade, 26(3), 561-583.

Kageyama, A. (1990). O novo padrão agrícola brasileiro: do complexo rural aos complexos agroindustriais. In G. Delgado (Ed.), Agricultura e políticas públicas (pp. 113223). Brasília: IPEA.

Lopes, J. R. (1981). Do latifúndio à empresa: unidade e diversidade do capitalismo no campo. Petrópolis: Vozes.

Lopes, J. R. L. (1978). Empresas e pequenos produtores no desenvolvimento do capitalismo agrário em São Paulo (1940-1970). Estudos CEBRAP, (22), 41-110.

Loureiro, M. R. (1977). Parceria e capitalismo. Rio de Janeiro: Zahar.

Loureiro, M. R. (1987). Terra, família e capital. Formação e expansão da pequena burguesia rural em São Paulo. Petrópolis: Vozes.

Mann, S., \& Dickinson, C. (1987). Obstáculos ao desenvolvimento da agricultura capitalista. Literatura Econômica, 9(1), 7-26.

Marighela, C., Borges, F. C., Alves, M., Valverde, O., Schiling, P., \& Facó, R. (1980). A questão agrária no Brasil: textos dos anos sessenta. São Paulo: Editora Brasil Debates.

Martine, G., \& Garcia, R. G. (1987). Os impactos sociais da modernização agrícola. São Paulo: Editora Caetés.

Martins, J. S. (1975). Capitalismo e tradicionalismo. São Paulo: Pioneira.

Martins, J. S. (1979). O cativeiro da terra. São Paulo: Hucitec.

Martins, J. S. (1981).Os camponeses e a política no Brasil. Petrópolis: Vozes.

Mello, M. C. I. (1975). O boia-fria: acumulação e miséria. Petrópolis: Vozes.

Moura, M. M. (1978). Os herdeiros da terra: parentesco e herança numa área rural. São Paulo: Hucitec.

Moura, M. M. (1988). Os deserdados da terra. Rio de Janeiro: Bertrand Brasil.

Müller, G. (1980). Estado, estrutura agrária e população. Petrópolis: Vozes.

Müller, G. (1989). Complexo agroindustrial e modernização agrária. São Paulo: Hucitec.

Nabuco, J. (1883). O abolicionismo. Rio de Janeiro: Nova Fronteira.

Navarro, Z. (2013). Agroecologia: as coisas em seu lugar (A Agronomia brasileira visita a terra dos duendes). Colóquio, 10(1), 11-45.

Navarro, Z., \& Buainain, A. M. (2017). The global driving of Brazilian agrarian development in the new century. In A. M. Buainain, R. Lanna, \& Z. Navarro (Eds.), Globalization 
and agriculture: redefining unequal development. (pp. 9-30). Lanham: Lexington Books.

Navarro, Z., \& Pedroso, M. T. M. (2019). Rural Brazil: the demise of its agrarian past, 1968-2018. In A. M. Buainain, R. Lanna, \& Z. Navarro (Eds.), Brazil: agricultural development in the new century (the rise of a global agro-food power) (cap. 2). Nova York: Routledge.

Oliveira, F. (1972). A economia brasileira: crítica à razão dualista. Estudos CEBRAP, (2), 5-82.

Palmeira, M. (1971). Latifundium et capitalisme: lecture critique d'un débat (Tese de doutodo). Paris: EHESS.

Prado Junior, C. (1979). A questão agrária. São Paulo: Brasiliense.

Rangel, I. (1988, Novembro 16). Fim de linha. Folha de São Paulo.

Rangel, I. (2005). Obras reunidas (2 volumes). Rio de Janeiro: Contraponto.

Rios, J. A. (1971). A sociologia rural no Brasil. Sua evolução, principais problemas e situação atual. Rio de Janeiro: SPLAN.

Sá Júnior, F. (1973). O desenvolvimento da agricultura nordestina e as funções das atividades de subsistência. Estudos CEBRAP, (3), 87-148.

Santos, J. V. (1978). Os colonos do vinho: estudo sobre a subordinação do trabalho camponês ao capital. São Paulo: Hucitec.

Santos, R. (2007). Agraristas políticos brasileiros. Brasília: Fundação Astrojildo Pereira.
Scherer-Warren, I. (1989). Movimentos sociais. Florianópolis: Editora da UFSC.

Schneider, S. (2003). A pluriatividade na agricultura familiar. Porto Alegre: UFRGS Editora.

Silva, J. G. (1981a). Progresso técnico e relações de trabalho na agricultura. São Paulo: Hucitec.

Silva, S. S. (1981b). Valor e renda da terra: o movimento do capital no campo. São Paulo: Polis.

Silva, J. G. (1982). A modernização dolorosa: estrutura agrária, fronteira agrária e trabalhadores rurais no Brasil. Rio de Janeiro: Zahar.

Silva, J. G. (1992). Fim do 'agribusiness' ou emergência da biotecnologia? Economia e Sociedade, 1(1), 163-167.

Silva, J. G. (1999). O novo rural brasileiro (Coleção Pesquisas, 1). Campinas: Instituto de Economia da Unicamp.

Silva, S. S. (1976). Expansão cafeeira e origens da indústria no Brasil. São Paulo: Alfa-Ômega.

Sorj, B. (1980). Estado e classes sociais na agricultura brasileira. Rio de Janeiro: Zahar.

Stédile, J. P. (1994). A questão agrária hoje. Porto Alegre: Editora da Universidade.

Szmrecsányi, T., \& Queda, O. (1972). Vida rural e mudança social. São Paulo: Editora Nacional.

Wilkinson, J. (1986). Estado, agroindústria e a pequena produção. São Paulo: Hucitec.

Wilkinson, J. (2008). Mercados, redes e valores. Porto Alegre: UFGRS Editora. 